\title{
Apical Membrane Chloride/Base Exchange in the Rat Proximal Convoluted Tubule
}

\author{
Robert J. Alpern \\ With the technical assistance of May Chambers \\ Department of Medicine, Cardiovascular Research Institute, University of California, San Francisco, California 94143
}

\begin{abstract}
To examine whether $\mathrm{Cl} /$ base exchange is present on the apical membrane of the proximal convoluted tubule, cell pH was measured fluorometrically in the in vivo microperfused rat proximal tubule with $\left(2^{\prime}, 7^{\prime}\right)$-bis(carboxyethyl)-(5,6)-carboxyfluorescein. The effect of luminal chloride addition was examined in tubules perfused symmetrically with chloride-free solutions. In the absence of inhibitors, luminal chloride addition did not affect cell pH. However, after inhibition of basolateral membrane anion transport with peritubular 4-acetamido-4'-isothiocyano-(2,2')disulfonic-stilbene (to amplify effects of apical membrane transport on cell pH), luminal chloride addition caused a small cell acidification (delta $\mathrm{pH}_{\mathrm{i}}=0.02$ ). When $1 \mathrm{mM}$ formate was added to the solutions, luminal chloride addition caused a larger change in cell $\mathrm{pH}$ (delta $\left.\mathrm{pH}_{1}=0.06\right)$ that was inhibited by $\left(4,4^{\prime}\right)$-diisothiocyano-(2,2')-disulfonic-stilbene. This stimulation of $\mathrm{Cl} /$ base exchange was not seen with $1 \mathrm{mM}$ acetate addition. These results demonstrate apical membrane $\mathrm{Cl} /$ base exchange, a significant fraction of which is dependent on the presence of formate and probably represents $\mathrm{Cl} /$ formate exchange.
\end{abstract}

\section{Introduction}

Sodium chloride absorption across the proximal convoluted tubule (PCT) ${ }^{1}$ occurs by paracellular and transcellular pathways (1-4). Transcellular $\mathrm{NaCl}$ absorption is electroneutral $(3,5,6)$, but the exact apical and basolateral membrane mechanisms remain obscure. Three mechanisms by which sodium and chloride can cross the apical membrane have been proposed: direct coupling between sodium and chloride transport, parallel sodium and chloride conductances, and parallel $\mathrm{Na} / \mathrm{H}$ and $\mathrm{Cl} /$ base exchangers (7).

$\mathrm{Na} / \mathrm{H}$ antiport in parallel with $\mathrm{Cl} /$ base exchange would lead to absorption of $\mathrm{NaCl}$ and secretion of a proton and a base that would then neutralize each other. Inhibition of $\mathrm{NaCl}$ absorption by inhibitors of red blood cell anion exchange first suggested that parallel exchangers might mediate apical membrane $\mathrm{NaCl}$

Address correspondence to Robert J. Alpern, M.D., Department of Internal Medicine, University of Texas Health Science Center at Dallas, 5323 Harry Hines Blvd., Dallas, TX 75235-9030.

Received for publication 22 August 1986.

1. Abbreviations used in this paper: BCECF, $\left(2^{\prime}, 7^{\prime}\right)$-bis(carboxyethyl)$(5,6)$-carboxyfluorescein; BCECF-AM, acetoxymethyl derivative of BCECF; DIDS, $\left(4,4^{\prime}\right)$-diisothiocyano-(2,2')-disulfonic-stilbene; MPD, mean paired difference; $P C T$, proximal convoluted tubule; $P S T$, proximal straight tubule; SITS, 4-acetamido-4'-isothiocyano-(2,2')-disulfonic-stilbene.

J. Clin. Invest.

(c) The American Society for Clinical Investigation, Inc. 0021-9738/87/04/1026/05 $\$ 1.00$

Volume 79, April 1987, 1026-1030 absorption (8). Subsequent studies in isolated apical membrane vesicles have disagreed with respect to the presence or absence of $\mathrm{Cl} / \mathrm{OH}$ exchange (9-15). Karniski and Aronson (16) found rapid $\mathrm{Cl} /$ formate exchange in these apical membranes.

The purpose of the present studies was to examine whether proximal tubular cells possess apical membrane $\mathrm{Cl} /$ base exchange. To accomplish this, cell $\mathrm{pH}$ was measured in the in vivo microperfused rat PCT using the pH-sensitive dye, $\left(2^{\prime}, 7^{\prime}\right)$ bis(carboxyethyl)-(5,6)-carboxyfluorescein (BCECF). The results demonstrate $\mathrm{Cl} / \mathrm{b}$ ase exchange, a significant fraction of which is dependent on the presence of formate.

\section{Methods}

Experiments were performed using male Wistar rats (Charles River Breeding Laboratories, Inc., Wilmington, MA) weighing $180-280 \mathrm{~g}$. The rats were prepared for microperfusion as previously described (17). Briefly, rats were anesthetized with an intraperitoneal injection of Inactin (100$120 \mathrm{mg} / \mathrm{kg}$ ) and placed on a heated table that maintained body temperature at $37^{\circ} \mathrm{C}$. The left kidney was exposed by a flank incision and was immobilized in a lucite cup. The ureter was cannulated (PE-50) to ensure the free drainage of urine. Rats were infused intravenously with a bicarbonate Ringer's solution (105 nM NaCl, $25 \mathrm{mM} \mathrm{NaHCO}_{3}, 4 \mathrm{mM}$

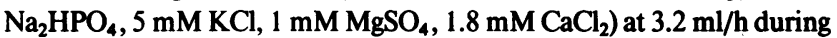
surgery and then $1.6 \mathrm{ml} / \mathrm{h}$ throughout the rest of the experiment. Proximal tubular transit time was measured following injection of $0.02 \mathrm{ml}$ of $10 \%$ lissamine green dye intravenously, and only those kidneys in which transit time was $<11 \mathrm{~s}$ were accepted for study.

Pipettes were placed using a dissecting microscope (E. Leitz Inc., Rockleigh, NJ). Peritubular capillaries were perfused as previously described $(18,19)$ with a $12-14 \mu \mathrm{m}$ tip pipette designed to allow rapid changes between two perfusion fluids. The lumen of a PCT was then perfused as previously described (19) using a technique of rapid retrograde perfusion similar to that described by Fromter and Gessner (20). First, tubules were perfused at $40 \mathrm{nl} / \mathrm{min}$ for 5-7 min using a thermally insulated microperfusion pump (Wolfgang Hampel, Berlin, FRG) with a solution containing the acetoxymethyl derivative of $\operatorname{BCECF}(18,21,22)$. The luminal perfusion fluid also contained $F D$ and $C$ green dye, which allowed delineation of more distal loops of the same nephron. This pipette will subsequently be referred to as the loading pipette. After 5-7 min, the loading pipette was removed and a second luminal pipette was placed in a more distal loop of the same nephron. This pipette was similar to that used in the peritubular capillary except that it had a smaller tip (7$9 \mu \mathrm{m})$. We have previously demonstrated that this technique allows control of luminal and peritubular fluid composition, and allows rapid changes in composition $(18,19)$.

The perfusion solutions are listed in Table I. All solutions were gassed with $7 \% \mathrm{CO}_{2} / 93 \% \mathrm{O}_{2}$. 4-Acetamido-4'-isothiocyano-(2,2')-disulfonicstilbene (SITS) was obtained from International Chemical and Nuclear, Cleveland, $\mathrm{OH}$, and $\left(4,4^{\prime}\right)$-diisothiocyano-(2,2')-disulfonic-stilbene (DIDS) from Sigma Chemical Co., St. Louis, MO. Ionized calcium concentration was measured on all perfusates (Nova 8, Nova Biomedical, Newton, MA) and was 1.3-1.5 mM. The luminal loading perfusion pipettes were filled with the control luminal solution (luminal perfusate used in the control period) containing $0.025 \%$ FD + $\mathrm{C}$ green dye No. 3 and $60 \mu \mathrm{g} / \mathrm{ml}\left(7.5 \times 10^{-5} \mathrm{M}\right)$ of the acetoxymethyl derivative of BCECF 
Table I. Perfusion Solutions

\begin{tabular}{|c|c|c|c|c|c|c|c|c|}
\hline & $25 \mathrm{HCO}_{3}$ & $25 \mathrm{HCO}_{3} / 0 \mathrm{Cl}$ & $5 \mathrm{HCO}_{3}$ & $5 \mathrm{HCO}_{3} / 0 \mathrm{Cl}$ & $25 \mathrm{HCO}_{3} /$ Form & $25 \mathrm{HCO}_{3} / \mathrm{Form} / 0 \mathrm{Cl}$ & $25 \mathrm{HCO}_{3} /$ Acet & $25 \mathrm{HCO}_{3} / \mathrm{Acet} / 0 \mathrm{Cl}$ \\
\hline $\mathrm{Na}^{+}$ & 147 & 147 & 147 & 147 & 147 & 147 & 147 & 147 \\
\hline $\mathbf{K}^{+}$ & 5 & 5 & 5 & 5 & 5 & 5 & 5 & 5 \\
\hline $\mathrm{Mg}^{++}$ & 1 & 1 & 1 & 1 & 1 & 1 & 1 & 1 \\
\hline $\mathrm{Ca}^{++}$ & 1.8 & 9.3 & 1.5 & 9.3 & 1.8 & 9.3 & 1.8 & 9.3 \\
\hline $\mathrm{Cl}^{-}$ & 128.6 & - & 148 & - & 127.6 & - & 127.6 & - \\
\hline Gluconate $^{-}$ & - & 143.6 & - & 163.6 & - & 142.6 & - & 142.6 \\
\hline $\mathrm{HCO}_{3}^{-}$ & 25 & 25 & 5 & 5 & 25 & 25 & 25 & 25 \\
\hline $\mathrm{HPO}_{4}^{-}$ & 1 & 1 & 1 & 1 & 1 & 1 & 1 & 1 \\
\hline $\mathrm{SO}_{4}^{-}$ & 1 & 1 & 1 & 1 & 1 & 1 & 1 & 1 \\
\hline Formate $^{-}$ & - & - & - & - & 1 & 1 & - & - \\
\hline Acetate $^{-}$ & - & - & - & - & - & - & 1 & 1 \\
\hline Glucose & 5 & 5 & 5 & 5 & 5 & 5 & 5 & 5 \\
\hline Alanine & 5 & 5 & 5 & 5 & 5 & 5 & 5 & 5 \\
\hline Urea & 5 & 5 & 5 & 5 & 5 & 5 & 5 & 5 \\
\hline
\end{tabular}

(BCECF-AM) (Molecular Probes, Inc., Junction City, OR). This compound does not fluoresce and is lipid soluble. It rapidly diffuses into cells where cytoplasmic esterases cleave off the acetoxymethyl groups forming the fluorescent BCECF, which has four to five negative charges and thus leaves the cell slowly (23). Cells were usually loaded until sufficient visible fluorescence was achieved. We have previously demonstrated that tubules perfused with BCECF-AM have normal rates of volume and bicarbonate transport (18).

Cell pH measurement. After placement of the pipettes, the dissecting microscope was moved out of position, and a Leitz epifluorescence microscope (MPV Compact system, E. Leitz Inc.) was moved into position. Cell $\mathrm{pH}$ was then measured as previously described (18). Using an adjustable measuring diaphragm, fluorescence was measured in the loop that had contained the loading pipette, distal to the hole left by removal of the loading pipette, and never through the glass pipettes. Measurements were made using a $10 \mathrm{X}$ objective. The measured loop was always well within the capillary perfusion area. Background fluorescence was measured in a tubule that did not contain the dye but was within the area of capillary perfusion. Background varied only slightly from tubule to tubule.

Analysis. As described previously (18), epifluorescent emission was measured at $530 \mathrm{~nm}$ during alternate excitation at 500 (pH-sensitive wavelength) and $450 \mathrm{~nm}$ (pH-insensitive wavelength), accomplished with interference filters (Corion Corp., Holliston, MA). Fluorescence was always measured with $500 \mathrm{~nm}$ excitation followed by $450 \mathrm{~nm}$ excitation, followed again by $500 \mathrm{~nm}$ excitation. All results were corrected by subtracting background. The fluorescence excitation ratio $\left(F_{500} / F_{450}\right)$ was calculated as the mean of the two 500 -nm excitation measurements divided by the $450-\mathrm{nm}$ excitation measurement. Use of the fluorescence excitation ratio provides a measurement unaffected by changes in dye concentration.

To convert fluorescent excitation ratios to an apparent cell $\mathrm{pH}$ value, results of our previously reported intracellular calibration were used (18, 24). Comparisons within the same tubule were made using the paired $t$ test. Group comparisons not within the same tubule were made using covariance analysis. Results are reported as mean \pm SE.

\section{Results}

To establish if $\mathrm{Cl} / \mathrm{HCO}_{3}$ exchange was present on the apical membrane, the effect of adding or removing luminal chloride was examined. Entry of chloride into the lumen from the peritubular interstitium was prevented by perfusing peritubular capillaries in all studies with chloride-free solutions. In the first three sets of studies, lumens were perfused with chloride-free solutions in the control and recovery periods and with chloridecontaining solutions in the experimental period, whereas capillaries were perfused with the same chloride-free solution in all three periods.

In the first set of studies, the lumen was perfused with a chloride-free solution containing $25 \mathrm{meq} / \mathrm{liter}$ bicarbonate (perfusate $25 \mathrm{HCO}_{3} / 0 \mathrm{Cl}$, Table I) in the control and recovery periods. In the experimental period, luminal chloride concentration was increased to $128.6 \mathrm{meq} / \mathrm{liter}$ (perfusate $25 \mathrm{HCO}_{3}$, Table I). Capillaries were perfused with solution $25 \mathrm{HCO}_{3} / 0 \mathrm{Cl}$ throughout. Cell pH was $7.29 \pm 0.03$ in the control period, $7.31 \pm 0.04$ in the experimental period, and $7.28 \pm 0.04$ in the recovery period (all changes NS; Fig. 1, solid circles).

To examine if a lower cell $\mathrm{pH}$ is required for apical membrane $\mathrm{Cl} / \mathrm{HCO}_{3}$ exchange, similar studies were next performed with an extracellular bicarbonate concentration of $5 \mathrm{meq} / \mathrm{liter}$. Lumen were perfused in the control and recovery periods with perfusate $5 \mathrm{HCO}_{3} / 0 \mathrm{Cl}$ and with solution $5 \mathrm{HCO}_{3}([\mathrm{Cl}]=148 \mathrm{meq} /$ liter) in the experimental period (Table I). Capillaries were perfused with solution $5 \mathrm{HCO}_{3} / 0 \mathrm{Cl}$ throughout. Once again, cell $\mathrm{pH}$ was unaffected by luminal chloride addition $(7.00 \pm 0.03$ in the control period, $6.99 \pm 0.05$ in the experimental period, and $6.97 \pm 0.04$ in the recovery period; Fig. 1, open circles).

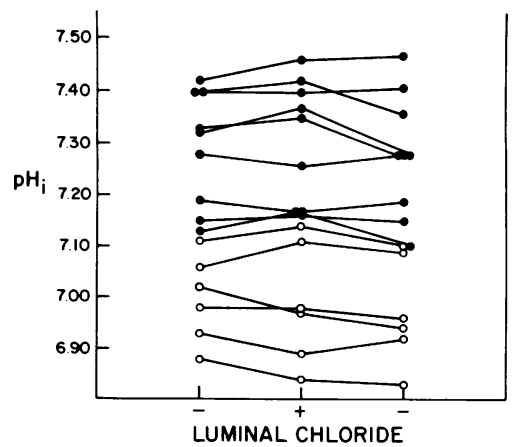

Figure 1. Effect of luminal chloride on cell pH. Lumen were perfused with solution $25 \mathrm{HCO}_{3} / 0 \mathrm{Cl}$ (closed circles) or $5 \mathrm{HCO}_{3} / 0 \mathrm{Cl}$ (open circles) in the control and recovery periods and with their respective chloride containing perfusate $\left(25 \mathrm{HCO}_{3}\right.$ and $\left.5 \mathrm{HCO}_{3}\right)$ in the experimental period (Table I). Capillaries were perfused with the luminal control solution throughout. 
To examine if a $\mathrm{Cl}$ /formate exchanger was present, the above studies were repeated with $1 \mathrm{mM}$ formate present in luminal and peritubular fluids. Lumens were perfused with solutions $25 \mathrm{HCO}_{3} / \mathrm{Form} / 0 \mathrm{Cl}$ in the control and recovery periods, and with solution $25 \mathrm{HCO}_{3} /$ Form in the experimental period (Table I). Capillaries were perfused with solution $25 \mathrm{HCO}_{3} / \mathrm{Form} / 0 \mathrm{Cl}$ throughout. Cell pH was $7.17 \pm 0.04$ in the control period, $7.19 \pm 0.04$ in the experimental period and 7.18 \pm 0.04 in the recovery period (all changes NS).

Thus, all studies reported thus far failed to demonstrate apical membrane $\mathrm{Cl} /$ base exchange. In previous studies, we found that basolateral membrane bicarbonate transport mechanisms were able to modify the response of cell $\mathrm{pH}$ to changes in apical membrane proton flux (19). As we (24) have recently found $\mathrm{Cl} /$ base exchange on the basolateral membrane, it is possible that increases in cell chloride concentration secondary to increases in luminal chloride concentration could drive basolateral membrane $\mathrm{Cl} /$ base exchange in a direction (bicarbonate influx) that would oppose apical membrane $\mathrm{Cl} /$ base exchange (bicarbonate efflux). In addition, basolateral membrane mechanisms could blunt any cell $\mathrm{pH}$ change (defend cell $\mathrm{pH}$ ). Therefore we next attempted to demonstrate apical membrane $\mathrm{Cl}$ /base exchange after inhibition of basolateral membrane bicarbonate transport with peritubular SITS. This maneuver was previously used by us to demonstrate apical membrane $\mathrm{Na} / \mathrm{H}$ exchange (19). In these studies (Figs. 2-5), peritubular capillaries were perfused with the control luminal solution with $1 \mathrm{mM}$ SITS added.

In the first studies, lumens were perfused with chloride-free solutions in the control and recovery periods (perfusate $25 \mathrm{HCO}_{3}$ / $0 \mathrm{Cl}$, Table I), and chloride was added in the experimental period (perfusate $25 \mathrm{HCO}_{3}$, Table I). In these studies, luminal chloride addition caused cell $\mathrm{pH}$ to decrease from $7.63 \pm 0.04$ to $7.60 \pm 0.04$ $(P<0.005$; Fig. 2). When chloride was removed in the recovery period, cell pH returned to $7.63 \pm 0.04(P<0.005)$. Thus after inhibition of the basolateral membrane transport mechanisms with peritubular SITS, we were able to demonstrate $\mathrm{Cl} /$ base exchange (mean paired difference $[\mathrm{MPD}]=0.02 \pm 0.01 \mathrm{pH} \mathrm{U}$ ).

To examine if formate addition increased the magnitude of this apparent $\mathrm{Cl} /$ base exchange, the above studies were repeated with $1 \mathrm{mM}$ formate added to all luminal and peritubular solutions (perfusates $25 \mathrm{HCO}_{3} / \mathrm{Form} / 0 \mathrm{Cl}$ and $25 \mathrm{HCO}_{3} /$ Form, Table I). Cell pH was $7.45 \pm 0.03$ in the absence of luminal chloride in the control period, decreased to $7.38 \pm 0.02$ upon luminal chloride addition, and returned to $7.44 \pm 0.02$ when luminal chloride was removed in the recovery period (all changes $P<0.001$; MPD $=0.06 \pm 0.01 \mathrm{pH} \mathrm{U}$; Fig. 3). In the presence of formate, luminal chloride addition had a greater effect on cell $\mathrm{pH}(0.06 \mathrm{pH} \mathrm{U})$ than in its absence $(0.02 \mathrm{pH} \mathrm{U} ; P<0.001)$.

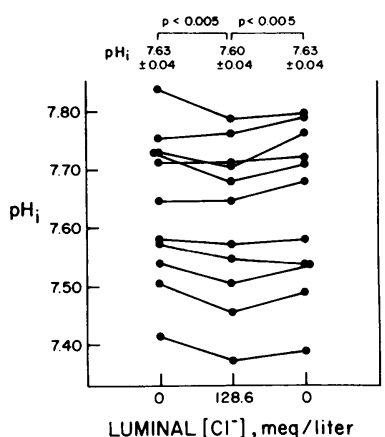

Figure 2. Effect of luminal chloride on cell $\mathrm{pH}$ after inhibition of basolateral membrane bicarbonate transport. Lumen were perfused with solution $25 \mathrm{HCO}_{3} / 0 \mathrm{Cl}$ in the control and recovery periods, and with solution $25 \mathrm{HCO}_{3}$ in the experimental period. Capillaries were perfused with solution $25 \mathrm{HCO}_{3} /$ $0 \mathrm{Cl}$ with $1 \mathrm{mM}$ SITS added throughout.

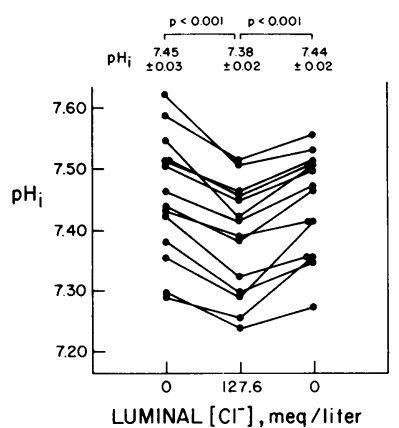

Figure 3. Effect of luminal chloride on cell $\mathrm{pH}$ after inhibition of basolateral membrane bicarbonate transport and in the presence of formate. Lumen were perfused with solution $25 \mathrm{HCO}_{3} / \mathrm{Form} / 0 \mathrm{Cl}$ in the control and recovery periods, and with solution $25 \mathrm{HCO}_{3} /$ Form in the experimental period. Capillaries were perfused with solution $25 \mathrm{HCO}_{3} / \mathrm{Form} / 0 \mathrm{Cl}$ with 1 mM SITS added throughout.

To examine if this stimulation of $\mathrm{Cl} / \mathrm{base}$ exchange was specific for formate, the above studies were repeated with $1 \mathrm{mM}$ acetate added to all luminal and peritubular solutions (perfusates $25 \mathrm{HCO}_{3} / \mathrm{Acet} / 0 \mathrm{Cl}$ and $25 \mathrm{HCO}_{3} /$ Acet, Table I). As above, SITS was added to the peritubular fluid. Cell pH was $7.52 \pm 0.07$ in the absence of luminal chloride in the control period, decreased to $7.50 \pm 0.07$ upon luminal chloride addition $(P<0.005)$, and returned to $7.52 \pm 0.07$ when luminal chloride was removed in the recovery period $(P<0.01 ; \mathrm{MPD}=0.03 \pm 0.01 \mathrm{pH} \mathrm{U}$; Fig. 4). In the presence of acetate, luminal chloride addition had an effect on cell $\mathrm{pH}$ less than that seen in the presence of formate $(P<0.001)$ and similar to that seen in the absence of formate (NS).

In the next set of studies, the sensitivity of $\mathrm{Cl} / \mathrm{base}$ exchange to luminal DIDS was examined. We chose to use luminal DIDS rather than SITS because Karniski and Aronson (16) and Schild et al. (25) used DIDS. For these studies, lumen and peritubular capillaries were perfused with perfusate $25 \mathrm{HCO}_{3} / \mathrm{Form} / 0 \mathrm{Cl}$ in the control and recovery periods (Table I). In the experimental period, chloride was added to the luminal fluid (perfusate $25 \mathrm{HCO}_{3} /$ Form). All luminal solutions contained $0.2 \mathrm{mM}$ DIDS, whereas the peritubular perfusate contained $1 \mathrm{mM}$ SITS. Cell $\mathrm{pH}$ was $7.46 \pm 0.01$ in the control period, $7.47 \pm 0.02$ in the experimental period, and $7.47 \pm 0.02$ in the recovery period (all changes NS; Fig. 5). Thus, apical membrane $\mathrm{Cl}$ /base exchange is blocked by DIDS.

\section{Discussion}

Lucci and Warnock (8) first found that luminal SITS and high concentrations of furosemide inhibit $\mathrm{NaCl}$ absorption in the rat PCT. Subsequently, Baum (26) found a similar effect of SITS and DIDS in the rabbit PCT. As these compounds all inhibit the red blood cell $\mathrm{Cl} / \mathrm{HCO}_{3}$ exchanger $(27,28)$, these studies suggested that parallel $\mathrm{Na} / \mathrm{H}$ and $\mathrm{Cl} / \mathrm{HCO}_{3}$ exchangers might

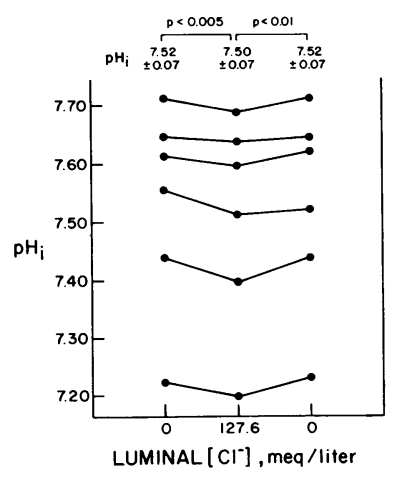

Figure 4. Effect of luminal chloride on cell $\mathrm{pH}$ after inhibition of basolateral membrane bicarbonate transport and in the presence of acetate. Lumen were perfused with solution $25 \mathrm{HCO}_{3} / \mathrm{Acet} / 0 \mathrm{Cl}$ in the control and recovery periods, and with solution $25 \mathrm{HCO}_{3} /$ Acet in the experimental period. Capillaries were perfused with solution $25 \mathrm{HCO}_{3} / \mathrm{Acet} / 0 \mathrm{Cl}$ with $1 \mathrm{mM}$ SITS added throughout. 


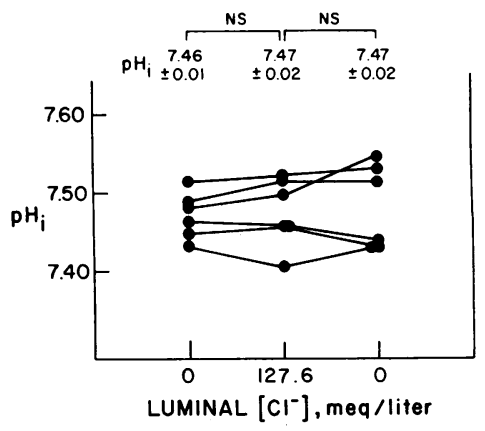

Figure 5. DIDS inhibition of apical membrane $\mathrm{Cl} /$ base exchange. Protocol as in Fig. 3, except that $0.2 \mathrm{mM}$ DIDS was present in all luminal perfusates.

effect apical membrane $\mathrm{NaCl}$ absorption. Baum (26) also found that luminal DIDS stimulated net bicarbonate absorption, consistent with $\mathrm{Cl} / \mathrm{HCO}_{3}$ exchange.

Studies in isolated brush border (apical) membranes have conflicted with respect to the mechanism of chloride transport. Whereas all of these vesicle studies have found a large chloride conductance, some have found $\mathrm{Cl} / \mathrm{OH}$ exchange (9-12), and some have not (13-15). Karniski and Aronson (16) demonstrated the presence of DIDS-sensitive $\mathrm{Cl} /$ formate exchange in apical membranes. These authors postulated that if the apical membrane was highly permeable to formic acid, then a $\mathrm{Cl}$ /formate exchanger would be equivalent to a $\mathrm{Cl} / \mathrm{OH}$ exchanger and, in parallel with $\mathrm{Na} / \mathrm{H}$ exchange, could affect apical membrane $\mathrm{NaCl}$ transport. In support of this thesis, Schild et al. (25) recently found that addition of small concentrations of formate to the luminal and bath fluid stimulated $\mathrm{NaCl}$ absorption in rabbit PCT and proximal straight tubule (PST) perfused in vitro. This effect was blocked by DIDS.

Studies that have attempted to demonstrate directly apical membrane anion exchange in intact tubules generally have been negative. Schwartz (29) measured the rate of luminal alkalinization in rabbit PCT perfused with acid solutions and was unable to find an effect of luminal chloride. Sasaki et al. (30) found no effect of luminal chloride removal on cell $\mathrm{pH}$ in the rabbit PST.

In the present studies, no effect of luminal chloride on cell $\mathrm{pH}$ was found in the presence of intact basolateral membrane transport mechanisms. These studies demonstrate that apical membrane anion exchangers are not important determinants of cell $\mathrm{pH}$. In addition, these studies do not support the presence of a significant apical membrane chloride conductance in vivo. As these cells possess a rheogenic potential difference-sensitive bicarbonate transport mechanism $(18,31-36)$, changes in cell potential difference would have been expected to cause changes in cell $\mathrm{pH}$.

In previous studies (19), we found that SITS-sensitive basolateral membrane transport mechanisms were able to modify the cell $\mathrm{pH}$ response to changes in luminal sodium and $\mathrm{pH}$. Therefore we repeated the present studies in the presence of peritubular SITS. In this setting, luminal chloride addition caused a significant $0.02 \mathrm{pH} U$ cell acidification that increased to 0.06 $\mathrm{pH} \mathrm{U}$ in the presence of formate but was only $0.03 \mathrm{pH} \mathrm{U}$ in the presence of acetate (Fig. 6). The presence of $\mathrm{Cl} /$ base exchange in the absence of formate suggests that some $\mathrm{Cl} / \mathrm{OH}, \mathrm{HCO}_{3}$ exchange is present. As peritubular SITS inhibits the cell's bicarbonate conductance $(18,31-36)$, these results cannot be explained by an apical membrane chloride conductance. The enhancement of $\mathrm{Cl} /$ base exchange by formate supports the presence of $\mathrm{Cl} /$ formate exchange as found by Karniski and Aronson (16). Karniski and Aronson (16) also found that acetate could not substitute for formate on this transporter, in agreement with the present results.

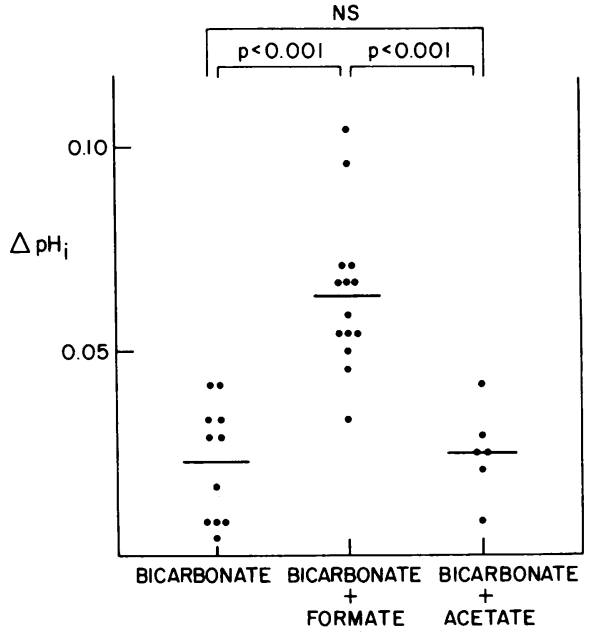

Figure 6. Comparison of the magnitudes of $\mathrm{Cl} /$ base exchange. The magnitude of the change in cell $\mathrm{pH}$ seen in each tubule upon luminal chloride addition and removal (average of the two $\mathrm{pH}$ changes) is plotted for each of the tubules in each of three protocols. In all studies, SITS was present in the peritubular capillary. The three protocols included studies performed in the presence of bicarbonate only (Fig. 2), studies with formate (Fig. 3), and those with acetate (Fig. 4).

These conclusions are consistent with the finding that active transcellular chloride absorption can be demonstrated in the in vitro perfused rabbit PCT in the absence of added formate (3, 25 ) but is accelerated by addition of formate (25). In the rat, studies that have demonstrated active chloride absorption have been performed with blood, possibly containing formate, in the capillaries $(1,4)$. The failure to consistently find $\mathrm{Cl} / \mathrm{OH}$ exchange in vesicle studies may be due to the small magnitude of exchange compared to the large magnitude of the chloride conductance (in the vesicles). Alternatively, it is possible that in our studies and in the rabbit tubule studies performed in the absence of formate, metabolic production by the proximal tubular cell maintains sufficient levels of formate in the cell.

In summary, the above studies demonstrate apical membrane stilbene-sensitive $\mathrm{Cl} /$ base exchange. More than half of this appears to be $\mathrm{Cl} /$ formate exchange with the remaining fraction probably $\mathrm{Cl} / \mathrm{OH}, \mathrm{HCO}_{3}$ exchange. These mechanisms, in parallel with $\mathrm{Na} / \mathrm{H}$ antiport, provide a pathway for $\mathrm{NaCl}$ absorption across the apical membrane. The secreted $\mathrm{H}^{+}$and $\mathrm{HCO}_{3}^{-}$or formate will neutralize each other in the lumen and then diffuse across the apical membrane as $\mathrm{CO}_{2}$ and formic acid, respectively.

\section{Acknowledgments}

The author is grateful to Floyd C. Rector, Jr. for his continuing support and advice throughout the performance of these studies. The author also gratefully acknowledges the excellent secretarial assistance of Gracie Bernacki.

These studies were supported by grant AM-27045 from the National Institute of Arthritis, Diabetes, and Digestive and Kidney Diseases, and by generous grants from Medical School Committee Hampton/Huntington Funds and the Hedco Foundation. Dr. Alpern is the recipient of a Clinical Investigator Award (AM-01229) from the National Institute of Arthritis, Diabetes, and Digestive and Kidney Diseases.

\section{References}

1. Green, R., J. H. V. Bishop, and G. Giebisch. 1979. Ionic requirements of proximal tubular sodium transport. III. Selective luminal anion substitution. Am. J. Physiol. 236:F268-F277. 
2. Jacobson, H. R. 1979. Characteristics of volume reabsorption in rabbit superficial and juxtamedullary proximal convoluted tubules. $J$. Clin. Invest. 63:410-418.

3. Baum, M., and C. A. Berry. 1984. Evidence for neutral transcellular $\mathrm{NaCl}$ transport and neutral basolateral chloride exit in the rabbit proximal convoluted tubule. J. Clin. Invest. 74:205-211.

4. Alpern, R. J., K. J. Howlin, and P. A. Preisig. 1985. Active and passive components of chloride transport in the rat proximal convoluted tubule. J. Clin. Invest. 76:1360-1366.

5. Howlin, K. J., R. J. Alpern, C. A. Berry, and F. C. Rector, Jr. 1986. Evidence for electroneutral sodium chloride transport in rat proximal convoluted tubule. Am. J. Physiol. 250:F644-F648.

6. Biagi, B. A., and G. Giebisch. 1978. Temperature dependence of transepithelial potential in isolated perfused rabbit proximal tubules. Am. J. Physiol. 236:F302-F310.

7. Rector, F. C., Jr. 1983. Sodium, bicarbonate, and chloride absorption by the proximal tubule. Am. J. Physiol. 244:F461-F471.

8. Lucci, M. S., and D. G. Warnock. 1979. Effects of anion-transport inhibitors on $\mathrm{NaCl}$ reabsorption in the rat superficial proximal convoluted tubule. J. Clin. Invest. 64:570-579.

9. Warnock, D. G., and V. J. Yee. 1981. Chloride uptake by brush border membrane vesicles isolated from rabbit renal cortex: coupling to proton gradients and $\mathrm{K}^{+}$diffusion potentials. J. Clin. Invest. 67:103115.

10. Shiuan, D., and S. W. Weinstein. 1984. Evidence for electroneutral chloride transport in rabbit renal cortical brush border membrane vesicles. Am. J. Physiol. 247:F837-F847.

11. Burnham, C., C. Munzesheimer, E. Rabon, and G. Sachs. 1982. Ion pathways in renal brush border membranes. Biochim. Biophys. Acta. 685:260-272.

12. Cassano, G., B. Stieger, and H. Murer. 1984. Na/H- and Cl/OHexchange in rat jejunal and rat proximal tubular brush border membrane vesicles. Pfluegers Arch. Eur. J. Physiol. 400:309-317.

13. Seifter, J. L., R. Knickelbein, and P. S. Aronson. 1984. Absence of $\mathrm{Cl}-\mathrm{OH}$ exchange and $\mathrm{NaCl}$ cotransport in rabbit renal microvillus membrane vesicles. Am. J. Physiol. 247:F753-F759.

14. Ives, H. E., A.-Y. Chen, and A. S. Verkman. 1986. Mechanism of coupling between $\mathrm{Cl}^{-}$and $\mathrm{OH}^{-}$transport in renal brush border membranes. Biochim. Biophys. Acta. 863:91-100.

15. Sabolic, I., and G. Burckhardt. 1983. Proton pathways in rat renal brush-border and basolateral membranes. Biochim. Biophys. Acta. 734:210-220.

16. Karniski, L. P., and P. S. Aronson. 1985. Chloride/formate exchange with formic acid recycling: a mechanism of active chloride transport across epithelial membranes. Proc. Natl. Acad. Sci. USA. 82:63626365.

17. Alpern, R. J. 1984. Bicarbonate-water interactions in the rat proximal convoluted tubule: an effect of volume flux on active proton secretion. J. Gen. Physiol. 84:753-770.

18. Alpern, R. J. 1985. Mechanism of basolateral membrane $\mathrm{H}^{+} /$ $\mathrm{OH}^{-} / \mathrm{HCO}_{3}^{-}$transport in the rat proximal convoluted tubule: a sodiumcoupled electrogenic process. J. Gen. Physiol. 86:613-637.

19. Alpern, R. J., and M. Chambers. 1986. Cell pH in the rat proximal convoluted tubule: regulation by luminal and peritubular $\mathrm{pH}$ and sodium concentration. J. Clin. Invest. 78:502-510.

20. Fromter, E., and K. Gessner. 1974. Active transport potentials, membrane diffusion potentials, and streaming potentials across rat kidney proximal tubule. Pfluegers Arch. Eur. J. Physiol. 351:85-98.

21. Moolenaar, W. H., R. Y. Tsien, P. T. van der Saag, and S. W. de Laat. 1983. $\mathrm{Na}^{+} / \mathrm{H}^{+}$exchange and cytoplasmic $\mathrm{pH}$ in the action of growth factors in human fibroblasts. Nature (Lond.). 304:645-648.

22. Rink, T. J., R. Y. Tsien, and T. Pozzan. 1982. Cytoplasmic pH and free $\mathrm{Mg}^{2+}$ in lymphocytes. J. Cell Biol. 95:189-196.

23. Thomas, J. A., R. N. Buchsbaum, A. Zimniak, and E. Racker. 1979. Intracellular pH measurements in Ehrlich ascites tumor cells utilizing spectroscopic probes generated in situ. Biochemistry. 18:22102218.

24. Alpern, R. J., and M. Chambers. 1987. Basolateral membrane $\mathrm{Cl} / \mathrm{HCO}_{3}$ exchange in the rat proximal convoluted tubule: Na-dependent and independent modes. J. Gen. Physiol. In press.

25. Schild, L., L. P. Karniski, P. S. Aronson, and G. Giebisch. 1986. Formate stimulates active $\mathrm{NaCl}$ transport in the rabbit proximal tubule. Kidney Int. 29:407. (Abstr.)

26. Baum, M. 1986. Parallel $\mathrm{Na}^{+} / \mathrm{H}^{+}$and $\mathrm{Cl}^{-} / \mathrm{HCO}_{3}^{-}\left(\mathrm{OH}^{-}\right)$antiporters transport $\mathrm{NaCl}$ in the rabbit proximal convoluted tubule (PCT). Kidney Int. 29:390. (Abstr.)

27. Cabantchik, Z. I., and A. Rothstein. 1972. The nature of the membrane sites controlling anion permeability of human red blood cells as determined by studies with disulfonic stilbene derivatives. J. Membr. Biol. 10:311-330.

28. Brazy, P. C., and R. B. Gunn. 1976. Furosemide inhibition of chloride transport in human red blood cells. J. Gen. Physiol. 68:583599.

29. Schwartz, G. J. 1983. Absence of $\mathrm{Cl}^{-}-\mathrm{OH}^{-}$or $\mathrm{Cl}^{-}-\mathrm{HCO}_{3}^{-}$exchange in the rabbit renal proximal tubule. Am. J. Physiol. 245:F462-F469.

30. Sasaki, S., Y. lino, T. Shiigai, and J. Takeuchi. 1984. Intracellular $\mathrm{pH}$ of isolated perfused rabbit proximal tubule: effects of luminal $\mathrm{Na}$ and $\mathrm{Cl}$. Kidney Int. 25:282. (Abstr.)

31. Boron, W. F., and E. L. Boulpaep. 1983. Intracellular pH regulation in the renal proximal tubule of the salamander: basolateral $\mathrm{HCO}_{3}^{-}$transport. J. Gen. Physiol. 81:53-94.

32. Burckhardt, B.-Ch., K. Sato, and E. Fromter. 1984. Electrophysiological analysis of bicarbonate permeation across the peritubular cell membrane of rat kidney proximal tubule. I. Basic observations. Pfluegers Arch. Eur. J. Physiol. 401:34-42.

33. Biagi, B. A., and M. Sohtell. 1986. Electrophysiology of basolateral bicarbonate transport in the rabbit proximal tubule. Am. J. Physiol. 250: F267-F272.

34. Akiba, T., R. J. Alpern, J. Eveloff, J. Calamina, and D. G. Warnock. 1986. Electrogenic sodium/bicarbonate cotransport in rabbit renal cortical basolateral membrane vesicles. J. Clin. Invest. 78:1472-1478.

35. Sasaki, S., K. Tomita, Y. Iino, T. Shiigai, and J. Takeuchi. 1986. Mechanism of bicarbonate exit across the basolateral membrane of rabbit proximal tubule. Kidney Int. 29:375. (Abstr.)

36. Grassl, S. M., and P. S. Aronson. $1986 . \mathrm{Na}^{+} / \mathrm{HCO}_{3}^{-}$co-transport in basolateral membrane vesicles isolated from rabbit renal cortex. $J$. Biol. Chem. 261:8778-8783. 